\title{
Synthesis and crystal structures of lanthanide 4-benzyloxy benzoates: Influence of electron-withdrawing and electron-donating groups on luminescent properties $\uparrow$
}

\author{
Sarika Sivakumar, ${ }^{a}$ M. L. P. Reddy, ${ }^{* a}$ Alan H. Cowley $^{b}$ and Kalyan V. Vasudevan ${ }^{b}$ \\ Received 21st August 2009, Accepted 14th October 2009 \\ First published as an Advance Article on the web 16th November 2009 \\ DOI: 10.1039/b917256d
}

Three new 4-benzyloxy benzoic acid derivatives [4-benzyloxy benzoic acid = HL1;

3-methoxy-4-benzyloxy benzoic acid = HL2; 3-nitro-4-benzyloxy benzoic acid = HL3] have been employed as ligands for the support of six lanthanide coordination compounds $\left[\mathrm{Tb}^{3+}=\mathbf{1}-\mathbf{3} ; \mathrm{Eu}^{3+}=\right.$ 4-6] with the aim of testing the influence of electron releasing (-OMe) or electron withdrawing $\left(-\mathrm{NO}_{2}\right)$ substituents on the photophysical properties. The new complexes have been characterized by a variety of spectroscopic techniques and two of the $\mathrm{Tb}^{3+}$ complexes [1 and 2] have been structurally authenticated by single-crystal X-ray diffraction. Compounds $\mathbf{1}$ and $\mathbf{2}$ crystallize in the monoclinic space group $\mathrm{P} 2_{1} / n$ and their molecular structures consist of homodinuclear species that are bridged by two oxygen atoms from two benzoate ligands. In the case of $\mathbf{1}$, the carboxylate ligands coordinate to the central $\mathrm{Tb}^{3+}$ ion in bidentate chelating and bidentate bridging modes. By contrast, three different coordination modes (bidentate chelating, bidentate bridging and monodentate) are observed in the case of compound 2. Examination of the packing diagrams for $\mathbf{1}$ and $\mathbf{2}$ revealed the presence of a one-dimensional molecular array that is held together by intermolecular hydrogen-bonding interactions. The incorporation of an electron-releasing substituent on position 3 of 4-benzyloxy benzoic acid increases the electron density of the ligand and consequently improves the photoluminescence of the $\mathrm{Tb}^{3+}$ complexes. On the other hand, the presence of an electron-withdrawing group at this position dramatically decreases the overall sensitization efficiency of the $\mathrm{Tb}^{3+}$-centered luminescence due to dissipation of the excitation energy by means of a $\pi^{*}$-n transition of the $\mathrm{NO}_{2}$ substituent along with the participation of the ILCT bands. The weaker photoluminescence of the $\mathrm{Eu}^{3+}$ complexes is attributable to the poor match of the triplet energy levels of the 4-benzyloxy benzoic acid derivatives with that of the emitting level of the central metal ion.

\section{Introduction}

The versatile photophysical properties of trivalent lanthanide ions continue to attract considerable attention owing to the wide range of potential applications in fields as diverse as bioassays, sensor systems and optical materials. ${ }^{1-4}$ Typically, due to the low extinction coefficients of the Laporte-forbidden f-f transitions, $\mathrm{Ln}^{3+}$ ions are excited indirectly by means of aromatic chromophores or "antennas" that possess a reasonably large molar absorption cross section. ${ }^{5}$ The choice of ligand for the so-called "antenna effect" plays a key role in constructing efficient lanthanide complexes. Two important requirements to be considered in selecting an "antenna" ligand are the strength of binding to the lanthanide metal and

${ }^{a}$ Chemical Sciences and Technology Division, National Institute for Interdisciplinary Science \& Technology (NIIST), C.S.I.R, Thiruvananthapuram695019 , India. E-mail: mlpreddy55@gmail.com

${ }^{b}$ Department of Chemistry and Biochemistry, The University of Texas at Austin, 1 University Station A5300, Austin, Texas, 78712

$\dagger$ Electronic supplementary information (ESI) available: NMR spectra of ligands, TG data, absorption, excitation, emission spectra and lifetime decay profiles of 4-6, excitation spectrum complex 3, room-temperature emission spectra of ligands HL1 to HL3, FT-IR and absorption data of ligands and complexes, procedures for calculating quantum yields and other photophysical data. CCDC reference numbers 729140 for $\mathbf{1}$ and 734105 for 2. For ESI and crystallographic data in CIF or other electronic format see DOI: $10.1039 / \mathrm{b} 917256 \mathrm{~d}$ the ultraviolet (UV) absorption properties of the ligand. Among a host of organic ligands, the aromatic carboxylates represent one of the most frequently used sensitizing ligands for enhancing lanthanide luminescence because they can chelate effectively to lanthanide cations via anionic carboxylate groups. Moreover, such carboxylate groups absorb UV radiation strongly and the absorbed energy is transferred efficiently to the lanthanide metal center. $^{6}$

Recently, the benzoate ligand class has been investigated extensively since it has been discovered that the carboxylate group interacts strongly with lanthanide cations and the delocalized $\pi$-electron system provides a strongly absorbing chromophore. ${ }^{7}$ As a consequence, several complexes of $\mathrm{Eu}^{3+}$ and $\mathrm{Tb}^{3+}$ with $o-, m$ - and $p$-nitrobenzoic acids have been synthesized, and their photophysical properties have been examined both in the solid state and in methanol solution. ${ }^{8}$ Typically, these compounds exhibit weak luminescence in the solid state and moderate quantum yields in methanol solution ( 1 and $3 \%$ for $\mathrm{Eu}^{3+}$ and $\mathrm{Tb}^{3+}$, respectively). In subsequent studies, it has been demonstrated that thiophenyl-derivatized nitrobenzoic acid ligands are superior sensitizers for $\mathrm{Eu}^{3+}$ and $\mathrm{Tb}^{3+} .{ }^{9}$ The intense fluorescent emissions of homodinuclear lanthanide complexes of 4-cyanobenzoic acid indicate that ligand-to- $\mathrm{Ln}^{3+}$ energy transfer is efficient and, furthermore, that coordinated water molecules do not quench the luminescence by nonradiative dissipation of energy. ${ }^{10}$ The 
$\mathrm{Tb}^{3+}$ complexes of $p$-aminobenzoates also exhibit strong luminescence due to efficient energy transfer from the triplet state of the ligand to the metal ion. ${ }^{11}$ Given the important potential applications of lanthanide carboxylates and the fascinating properties of these ligands, we were prompted to prepare a new series of lanthanide complexes supported by 4-benzyloxy benzoic acid ligands that had been substituted by an electron-releasing (-OMe) or electron-withdrawing $\left(-\mathrm{NO}_{2}\right)$ moiety at the 3-position. These groups influence the distribution of $\pi$-electron density in the ligand system. As a consequence, the effective charges on the atoms coordinated to the $\mathrm{Ln}^{3+}$ ions can be modified and the interaction of the ligands with the metal ion can be tuned. In turn, modification of the energies of the ligand-metal charge transfer states (LMCTS) and the positions of the triplet levels is anticipated to have a profound influence on the luminescent properties of the various $\mathrm{Ln}^{3+}$ ions. In the present work, several derivatives of 4-benzyloxy benzoic acids have been designed, synthesized and utilized for the assembly of $\mathrm{Tb}^{3+}, \mathrm{Eu}^{3+}$ and $\mathrm{Gd}^{3+}$ complexes. Two of the new lanthanide 4-benzyloxy benzoates have been structurally characterized by single-crystal X-ray diffraction. Finally, the photophysical properties of all the new lanthanide benzoate complexes have been investigated and correlated with the electrondonating or withdrawing characteristics of the substituents on the targeted ligands.

\section{Results and discussion}

\section{Synthesis and characterization}

The ligands HL1, HL2 and HL3 were prepared from the corresponding hydroxy benzoic acids in three steps as described in the Experimental section (Scheme 1). The overall yields ranged from 69 to $74 \%$. The new ligands were characterized by ${ }^{1} \mathrm{H}$ NMR and ${ }^{13} \mathrm{C}$ NMR (Fig. S1-S3 in ESI $\dagger$ ), mass spectroscopy and elemental analysis. The synthetic procedures for the $\mathrm{Ln}^{3+}$ complexes 1-9 are described in the Experimental section. The elemental analyses for these complexes reveal that each $\mathrm{Ln}^{3+}$ ion has reacted with the corresponding benzyloxy benzoic acid ligand in a metal-to-ligand mole ratio of 1:3. In order to investigate the coordination modes of the ligands to the $\mathrm{Ln}^{3+}$ ions, the FT-IR spectra of complexes 1-9 were compared with those of the free ligands. In their ionic form these ligands exhibit intense IR peaks at $\sim 1450$ and $\sim 1680 \mathrm{~cm}^{-1}$ which are attributable to the symmetric $v_{s}(C=O)$ and asymmetric $\mathrm{v}_{\mathrm{as}}(\mathrm{C}=\mathrm{O})$ vibrations, respectively. In each of the complexes
1-9, the absence of $v(\mathrm{COOH})$ absorption bands of the ligands at $\sim 1690 \mathrm{~cm}^{-1}$ is indicative of the coordination of ligands HL1, HL2 or HL3 to the respective lanthanide ion. A further distinguishing characteristic is that the asymmetric and symmetric stretching vibrational modes of the carboxylic acids are split into two peaks (see Table $\mathrm{S} 1$ in ESI $\dagger$ ). Complexes 1-9 also exhibit asymmetric and symmetric stretching vibrations $\left(\Delta \mathrm{v}_{(\mathrm{C}=0)}=\mathrm{v}_{\mathrm{as}}-\mathrm{v}_{\mathrm{s}}\right)$ in the ranges 228288 and $147-176 \mathrm{~cm}^{-1}$, which in turn implies that the carboxylate groups are coordinated to the $\mathrm{Ln}^{3+}$ ions in bidentate bridging, chelate and monodentate modes. ${ }^{12}$ Furthermore, the IR spectra of 1-9 also exhibit a broad band around $3400 \mathrm{~cm}^{-1}$, which is characteristic of an $\mathrm{O}-\mathrm{H}$ stretching vibration and thus indicative of the presence of coordinated solvent molecules. Likewise, the peaks detected in the $1030-1040 \mathrm{~cm}^{-1}$ region for some of the complexes imply the presence of coordinated DMSO molecules. ${ }^{6 \mathrm{~d}}$ In each case, the peaks are red-shifted with respect to that of unligated DMSO $\left(1047 \mathrm{~cm}^{-1}\right)$. The existence of solvent molecules in the first coordination sphere of $\mathbf{1} \mathbf{- 3}$ received further confirmation from thermogravimetric analysis. Thus, the initial weight loss of approximately $3 \%$ in the temperature range $180-200{ }^{\circ} \mathrm{C}$ is attributable to the loss of coordinated water molecules, and the second weight loss in the temperature range $260-320{ }^{\circ} \mathrm{C}$ corresponds to the loss of DMSO molecules (Fig. S4 in ESI $\dagger$ ). ${ }^{13}$ In the case of complex 2 , the weight loss at $120{ }^{\circ} \mathrm{C}$ corresponds to the loss of coordinated methanol. Further decomposition was evident in the temperature range $400-1000^{\circ} \mathrm{C}$.

\section{X-ray crystallography}

The single-crystal $\mathrm{X}$-ray structures of complexes of $\mathrm{Tb}_{2}(\mathrm{~L} 1)_{6}(\mathrm{DMSO})_{2}\left(\mathrm{H}_{2} \mathrm{O}\right)_{2} \quad$ (1) and $\mathrm{Tb}_{2}(\mathrm{~L} 2)_{6}(\mathrm{MeOH})_{2}\left(\mathrm{H}_{2} \mathrm{O}\right)_{4}$ (2) were determined and the molecular structures are depicted in Figs. 1 and 2, respectively. The crystal data and data collection parameters are presented in Table 1, and a selection of pertinent bond lengths and bond angles appears in Table 2. Compounds 1 and 2 both crystallize in the monoclinic space group $\mathrm{P} 2_{1} / n$. Each complex is dimeric and features two $\mathrm{Tb}^{3+}$ ions surrounded by six 4-benzyloxy benzoic acid ligands. The dimeric structures of $\mathbf{1}$ and 2 both feature an inversion center thus indicating that both terbium ions reside in equivalent chemical environments. The $\mathrm{Tb}$ - Tb distances of 4.555 and $4.760 \AA$ for $\mathbf{1}$ and $\mathbf{2}$, respectively fall within the range that has been observed for $\mathrm{Tb}^{3+}$-carboxylate complexes that feature the bridging bidentate coordination mode. ${ }^{13 c, 14}$

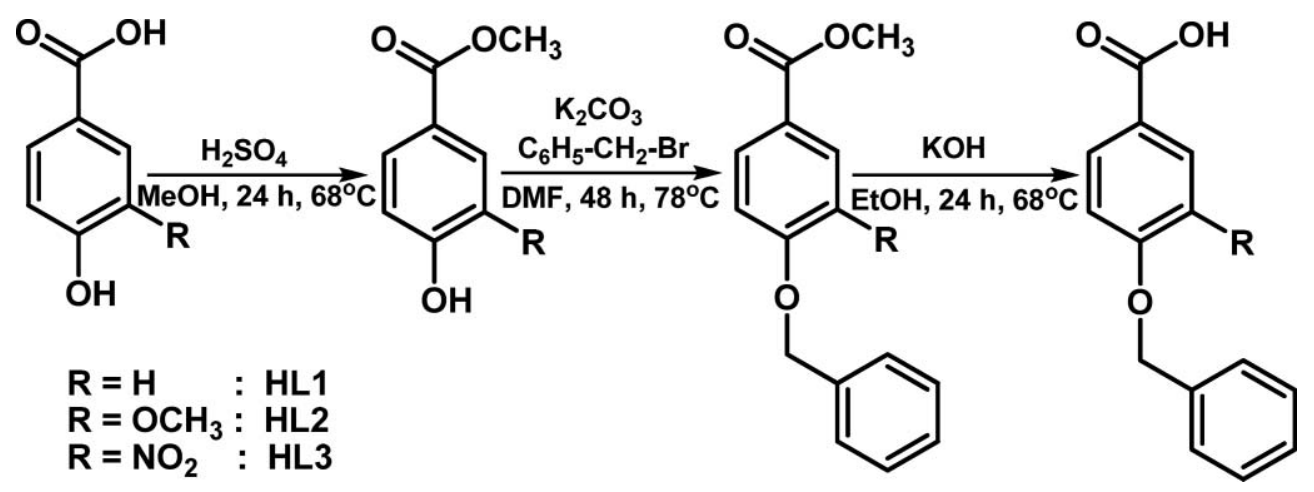

Scheme 1 Synthetic procedures for ligands HL1-HL3. 


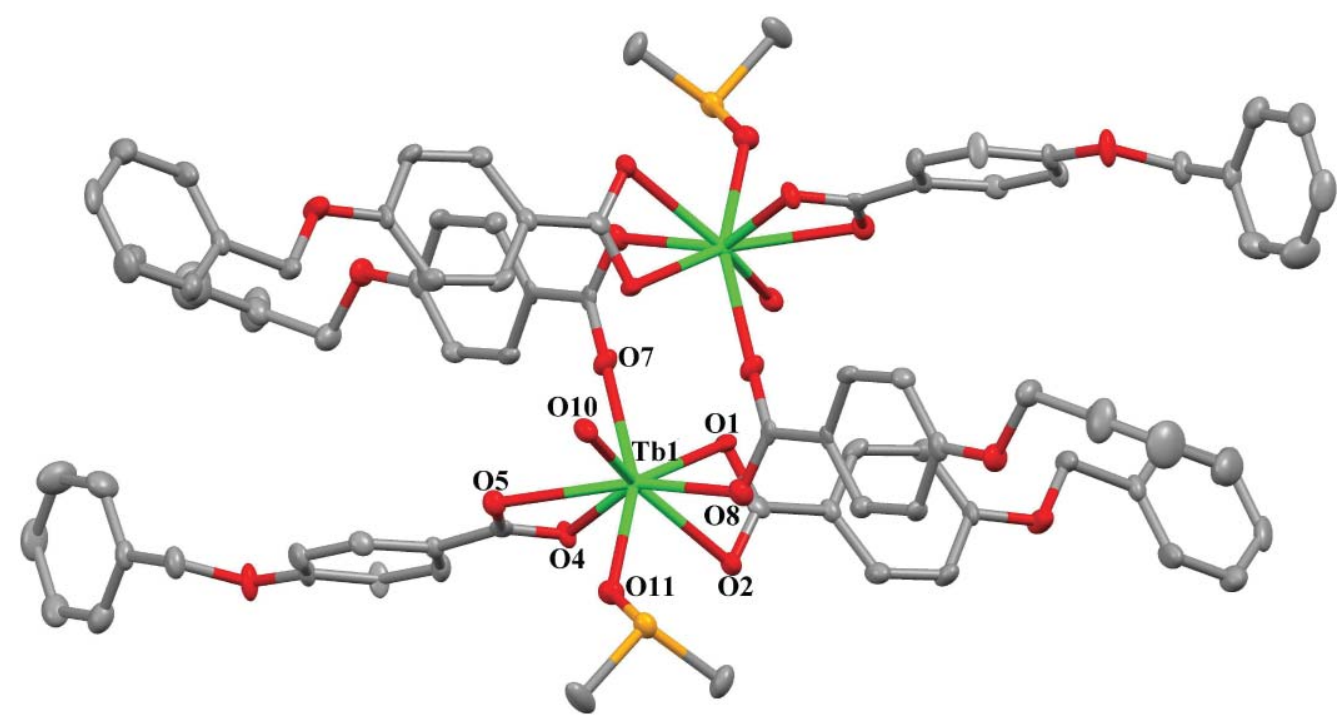

Fig. 1 Asymmetric unit of complex 1 with thermal ellipsoids shown at the $30 \%$ probability level and all hydrogen atoms omitted for clarity.

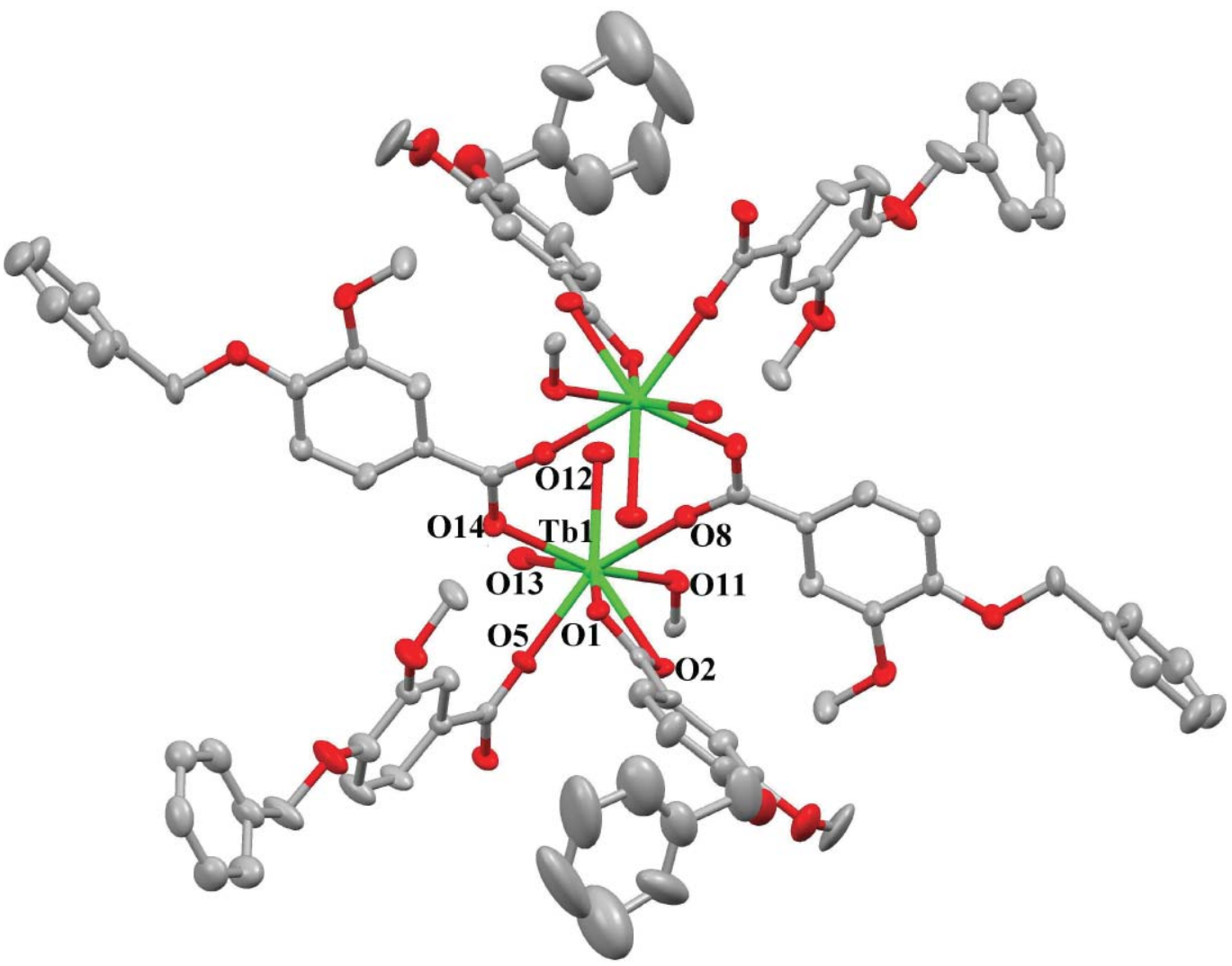

Fig. 2 Asymmetric unit of complex 2 with thermal ellipsoids shown at the $30 \%$ probability level and all hydrogen atoms omitted for clarity.

The structure of 1 depicted in Fig. 1 consists of an asymmetric dimer in which the $\mathrm{Tb}^{3+}$ ions occupy equivalent positions and are connected by the carboxylate groups of two benzoate ligands. Both carboxylate groups are attached in a bidentate bridging fashion and bind simultaneously to two $\mathrm{Tb}^{3+}$ ions. Each $\mathrm{Tb}^{3+}$ ion is further coordinated to two bidentate chelating carboxylate groups, one water molecule and one dimethylsulfoxide (DMSO) molecule hence each metal ion is eight-coordinate. The coordination polyhedra can be best described as distorted square antiprisms of approximately $\mathrm{C}_{2 \mathrm{v}}$ symmetry in which six oxygen atoms belong to the three 4-benzyloxy benzoate moieties and two oxygen atoms are provided by one water and one DMSO molecule. In the case of 1 , the $\mathrm{Tb}-\mathrm{O}$ bond lengths range from 2.282 to $2.517 \AA$. The longest $\mathrm{Tb}-\mathrm{O}$ bonds involve the oxygen atoms of the bidentate

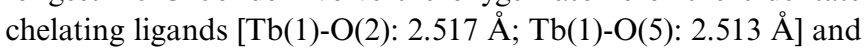
the shortest such bond is associated with the bridging carboxylate ligand [ $\mathrm{Tb}(1)-\mathrm{O}(7): 2.282 \AA]$. On the other hand, the Tb-O bond distances for the coordinated water and DMSO molecules 
Table 1 Crystallographic and refinement data for $\mathbf{1}$ and $\mathbf{2}$

\begin{tabular}{lll}
\hline & $\mathbf{1}$ & $\mathbf{2}$ \\
\hline formula & $\mathrm{C}_{88} \mathrm{H}_{82} \mathrm{O}_{22} \mathrm{~S}_{2} \mathrm{~Tb}_{2}$ & $\mathrm{C}_{92} \mathrm{H}_{94} \mathrm{O}_{30} \mathrm{~Tb}_{2}$ \\
fw & 1873.50 & 1997.51 \\
cryst sys & Monoclinic & Monoclinic \\
cryst size & $0.24 \times 0.06 \times 0.04$ & $0.2 \times 0.06 \times 0.04$ \\
$\mathrm{Temp} / \mathrm{K}$ & $153(2)$ & $153(2)$ \\
$a / \AA$ & $8.5769(17)$ & $19.359(4)$ \\
$b / \AA$ & $17.011(3)$ & $23.771(5)$ \\
$c / \AA$ & $27.749(6)$ & $9.4710(19)$ \\
$\alpha /^{\circ}$ & 90 & 90 \\
$\beta{ }^{\circ}$ & $91.83(3)$ & $91.62(3)$ \\
$\gamma /^{\circ}$ & 90 & 90 \\
$V / \AA^{3}$ & $4046.6(14)$ & $4356.6(15)$ \\
$Z$ & 2 & 2 \\
$\left.\mathrm{D}_{\text {calcd }} / \mathrm{g} \mathrm{cm}\right)^{-1}$ & 1.538 & 1.523 \\
$\mu(\mathrm{Mo} \mathrm{K} \alpha) / \mathrm{mm}^{-1}$ & 1.860 & 1.694 \\
$F(000)$ & 1896 & 2032 \\
$R 1[I>2 \sigma(I)]$ & 0.0566 & 0.0543 \\
$\mathrm{w} R 2[I>2 \sigma(I)]$ & 0.0889 & 0.1100 \\
$R 1($ all data $)$ & 0.1239 & 0.0913 \\
$\mathrm{w} R 2($ all data $)$ & 0.1177 & 0.1219 \\
gof & 0.986 & 1.148 \\
\hline
\end{tabular}

Table 2 Selected bond lengths $(\AA)$ and angles $\left({ }^{\circ}\right)$ for $\mathbf{1}$ and $\mathbf{2}$

\begin{tabular}{llll}
\hline $\mathbf{1}$ & & $\mathbf{2}$ & \\
\hline Tb1-Tb2 & 4.555 & Tb1-Tb2 & 4.760 \\
Tb1-O1 & $2.392(4)$ & Tb1-O1 & $2.469(4)$ \\
Tb1-O2 & $2.517(4)$ & Tb1-O2 & $2.504(5)$ \\
Tb1-O4 & $2.390(3)$ & Tb1-O5 & $2.273(4)$ \\
Tb1-O5 & $2.513(4)$ & Tb1-O8 & $2.292(5)$ \\
Tb1-O8 & $2.409(4)$ & Tb1-O11 & $2.337(4)$ \\
Tb1-O7 & $2.282(4)$ & Tb1-O12 & $2.423(5)$ \\
Tb1-O10 & $2.368(4)$ & Tb1-O13 & $2.446(5)$ \\
Tb1-O11 & $2.302(4)$ & Tb1-O14 & $2.332(5)$ \\
O1-Tb1-O2 & $53.14(13)$ & O1-Tb1-O2 & $52.34(14)$ \\
O4-Tb1-O5 & $53.21(12)$ & O5-Tb1-O1 & $78.75(16)$ \\
O7-Tb1-O8 & $113.82(14)$ & O5-Tb1-O2 & $73.35(16)$ \\
O11-Tb1-O5 & $74.57(13)$ & O8-Tb1-O14 & $108.20(16)$ \\
O11-Tb1-O10 & $80.79(13)$ & O12-Tb1-O11 & $79.64(16)$ \\
O11-Tb1-O2 & $82.20(13)$ & O13-Tb1-O12 & $69.93(16)$ \\
O10-Tb1-O8 & $78.13(14)$ & O13-Tb1-O11 & $79.32(17)$ \\
\hline
\end{tabular}

[Tb(1)-(O10): $2.362 \AA$ and Tb(1)-O(11): $2.302 \AA$, respectively] are shorter than those for the bidentate chelating benzoates. Similar trends in bond lengths have been reported by de BettencourtDias and Viswanathan for dimeric $\mathrm{Eu}^{3+}$ and $\mathrm{Tb}^{3+}$ complexes of thiophenyl-derivatized nitrobenzoate ligands. ${ }^{9}$ A detailed analysis of the packing diagram for $\mathbf{1}$ evidences an intermolecular hydrogen bonding interaction between C8-H8B of a benzyl moiety and O2 of a carboxylate group with an H8B-O2 separation of $2.458 \AA$ and an angle of $159.3^{\circ}{ }^{15}$ In addition to this strong intermolecular hydrogen bonding interaction, a $\mathrm{C}-\mathrm{H}-\pi$ interaction between C44-H44A of a DMSO molecule and the phenyl ring C2-C7 of a 4-benzyloxy benzoic acid ligand is also evident in the case of $\mathbf{1}$. The interplay of these two interactions results in a one-dimensional array when viewed along the direction of the $c$ axis (Fig. 3). In the case of compound $\mathbf{2}$, all of the 4-benzyloxy benzoic acid groups are coordinated to the $\mathrm{Tb}^{3+}$ ion and three different coordination modes can be recognized. Specifically, the carboxylato groups O2-C1-O1 adopt a chelating mode in which two $\mathrm{O}$ atoms coordinate to the same $\mathrm{Tb}^{3+}$ ion. In turn, the carboxylato groups O8-C31-O14 adopt a bridging binding mode in which two $\mathrm{O}$ atoms coordinate to two different $\mathrm{Tb}^{3+}$ ions to form a bidentate bridge, and finally one carboxylate ligand binds in a monodentate fashion via a single oxygen atom (O5) to the $\mathrm{Tb}^{3+}$ ion. The monodentate binding of a carboxylic acid ligand to a lanthanide center is somewhat unusual. Finally, the coordination sphere of the metal ion is completed by ligation of two water molecules and one methanol molecule bonded via $\mathrm{O}(12), \mathrm{O}(13)$ and $(\mathrm{O} 11)$, thus resulting in a coordination number of eight at each $\mathrm{Tb}^{3+}$ center. The shortest $\mathrm{Tb}-\mathrm{O}$ bond distance is associated with the monodentate carboxylate ligand $[\mathrm{Tb}(1)-\mathrm{O}(5): 2.273 \AA]$ and the longest such bonds are formed by the bidentate chelating carboxylate ligand $[\mathrm{Tb}(1)-\mathrm{O}(2): 2.504 \AA]$. Finally, scrutiny of the packing diagram for 2 reveals the presence of a one-dimensional molecular array aligned along the $c$ axis which involves an intermolecular hydrogen bonding interaction between the $\mathrm{C}(27)-\mathrm{H}(27)$ bond of the phenyl ring of one of the carboxylate ligands and $\mathrm{O}(6)$ of the methoxy group with a separation of $2.566 \AA[\mathrm{H}(27)-\mathrm{O}(6)]$ at an angle of $150.35^{\circ}$ [C(27)-H(27)-O(6) (Fig. 4)].

\section{UV-vis spectra}

The UV-vis absorption spectra of the ligands HL1-HL3 and their $\mathrm{Ln}^{3+}$ complexes, which were recorded in $\mathrm{CH}_{3} \mathrm{CN}$ solution $(c=2 \times$ $\left.10^{-5} \mathrm{M}\right)$ at room temperature, are presented in Fig. 5 and Figs. S5S6 (in ESI $\dagger$ ). The salient spectral features are summarized in Table S2 (in ESI $\dagger$ ). The absorption maxima at 253, 260 and $238 \mathrm{~nm}$ for ligands HL1-HL3 are attributable to the ${ }^{1} \pi-\pi^{*}$ transitions. Broad, weak absorptions at $295 \mathrm{~nm}$ (HL2) and $318 \mathrm{~nm}$ (HL3) may be due to the intraligand transitions (ILCT). ${ }^{16}$ Interestingly, the UV-vis maximum band is red-shifted to $260 \mathrm{~nm}$ in the case of the HL2 ligand, thus implying that the degree of conjugation increases and that the ${ }^{1} \pi-\pi^{*}$ energy level is lowered by introduction of the methoxy group. On the other hand, the absorption maximum for the HL3 ligand is blue shifted by $15 \mathrm{~nm}$ in comparison with that of HL1 due to the presence of an electron-withdrawing nitro group, which raises the ${ }^{1} \pi-\pi^{*}$ energy level. No significant changes are apparent in the shapes of the absorption bands upon formation of the lanthanide complexes. Each absorption maximum is red shifted by $3-10 \mathrm{~nm}$, which is a consequence of enlargement of the conjugate structures of the ligands following coordination to the lanthanide ions. The absorption coefficients for the complexes are 5.3-6 times larger than those for the free ligands, thus indicating the presence of six benzoate ligands per homodinuclear lanthanide complex. Furthermore, the large molar absorption coefficients for the ligands indicate that the carboxylic acids have a strong ability to absorb light.

\section{Steady-state photoluminiscence}

In order to elucidate the energy transfer processes in the new $\mathrm{Ln}^{3+}$ complexes, it was necessary to determine the singlet and triplet energy levels of the ligands HL1-HL3. The singlet $\left({ }^{1} \pi \pi^{*}\right)$ energy levels of these ligands were estimated by reference to the wavelengths of the UV-vis absorption edges of $\mathrm{Gd}^{3+}$ complexes 7-9. The relevant values were $307 \mathrm{~nm}\left(32573 \mathrm{~cm}^{-1}\right), 342 \mathrm{~nm}$ $\left(29239 \mathrm{~cm}^{-1}\right)$ and $279 \mathrm{~nm}\left(35842 \mathrm{~cm}^{-1}\right)$ for HL1, HL2 and HL3, respectively (see Fig. 5 and Figs. S5 and S6 in ESI $\dagger$ ). The triplet energy levels $\left({ }^{3} \pi \pi^{*}\right)$ of the ligands were calculated by reference to the lower wavelength emission edges $\left(382 \mathrm{~nm}: 26178 \mathrm{~cm}^{-1}\right.$, 


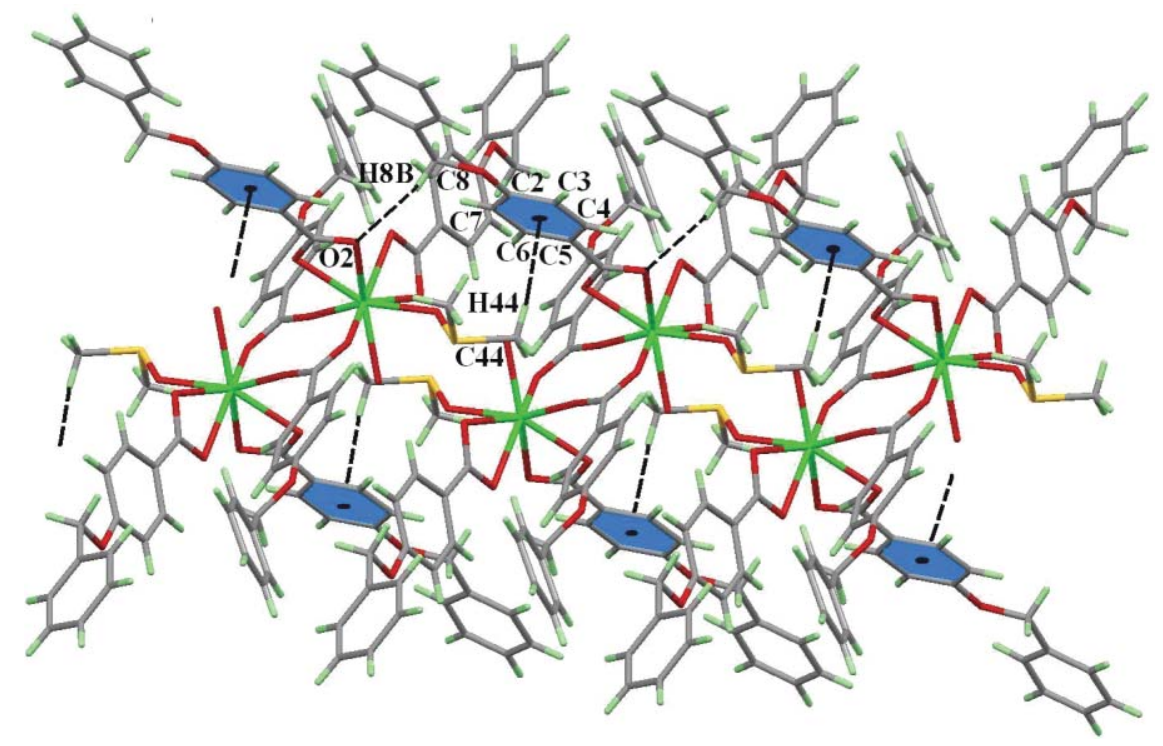

Fig. 3 View of complex 1 showing (a) the intermolecular hydrogen bonding interactions involving C8-H8B of the benzyl moiety and O2 of the carboxylate group and (b) the $\mathrm{CH}-\pi$ interactions between $\mathrm{C} 44-\mathrm{H} 44$ of a DMSO molecule and the phenyl ring C2-C7.

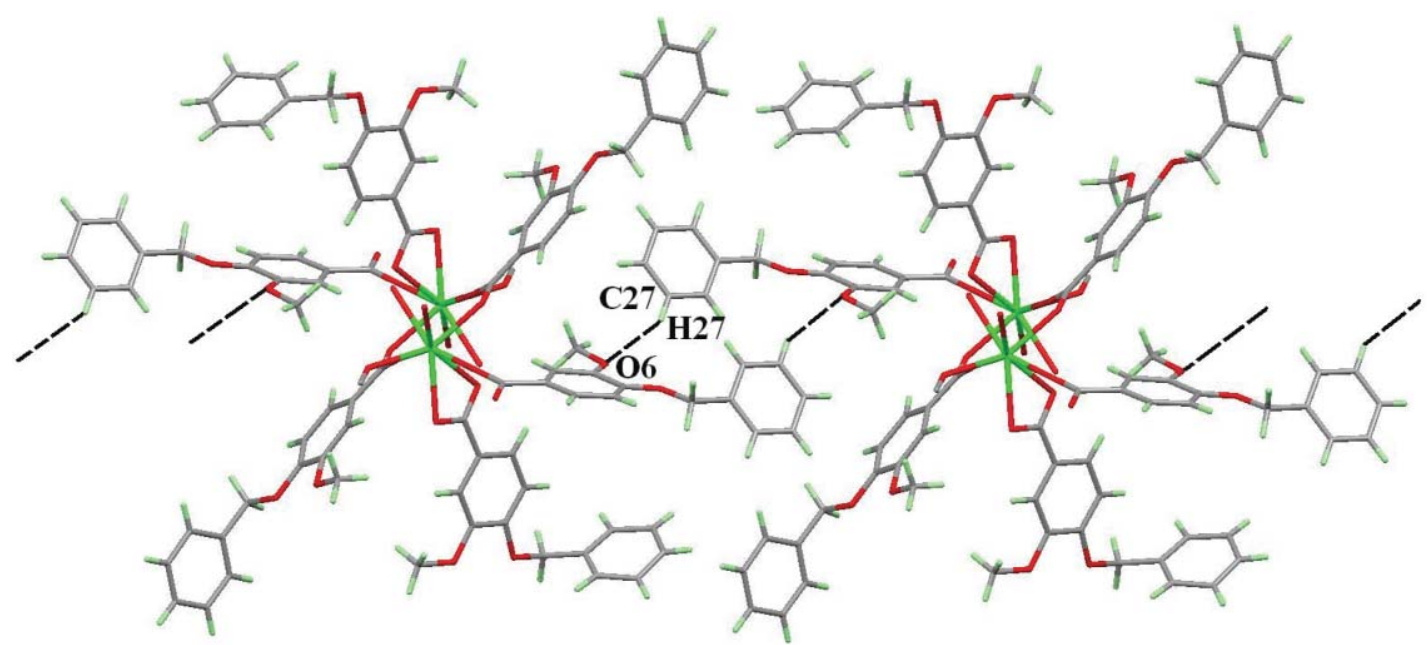

Fig. 4 View of complex 2 showing the intermolecular hydrogen bonding interactions between the phenyl C27-H27 bond and O6 of the methoxy group.

$403 \mathrm{~nm}: 24813 \mathrm{~cm}^{-1}, 401 \mathrm{~nm}: 24937 \mathrm{~cm}^{-1}$ for HL1, HL2 and HL3, respectively) from the low-temperature phosphorescence spectra of the $\mathrm{Gd}^{3+}$ complexes of the pertinent 4-benzyloxy benzoic acids (Fig. 6). Because there is a large energy gap (ca. $32000 \mathrm{~cm}^{-1}$ ) between the ${ }^{8} \mathrm{~S}_{7 / 2}$ ground state and the first ${ }^{6} \mathrm{P}_{7 / 2}$ excited state of the $\mathrm{Gd}^{3+}$ ion, it cannot accept any energy from the first excited triplet state of the ligand via intramolecular ligand-to-metal energy transfer. ${ }^{17}$ Thus the phosphorescence spectra of complexes 7-9 actually reveal the triplet energy levels $\left({ }^{3} \pi \pi^{*}\right)$ of the ligands HL1, HL2 and HL3 in the $\mathrm{Ln}^{3+}$ complexes. It is interesting to note that the triplet energy levels of all of the ligands lie above the energy of the main emitting level of ${ }^{5} \mathrm{D}_{4}$ for $\mathrm{Tb}^{3+}$ or ${ }^{5} \mathrm{D}_{0}$ for $\mathrm{Eu}^{3+}$, thus indicating that these ligands can act as antennas for the photosensitization of trivalent $\mathrm{Ln}^{3+}$ ions.

The solid state excitation and emission spectra of $\mathrm{Tb}^{3+}$ complexes 1-3 recorded at room-temperature are displayed in Figs. 79. The excitation spectra of these complexes monitored around the intense ${ }^{5} \mathrm{D}_{4} \rightarrow{ }^{7} \mathrm{~F}_{5}$ transition of the $\mathrm{Tb}^{3+}$ ion in the solid state overlap the absorption spectra of the ligands in the $250-350 \mathrm{~nm}$ region, thus indicating a very efficient energy transfer from the ligand to the $\mathrm{Tb}^{3+}$ center. ${ }^{18,19}$ The broad band observed between 250 and $350 \mathrm{~nm}$ in the excitation spectra of all of the $\mathrm{Tb}^{3+}$ complexes can be attributed to the $\pi-\pi^{*}$ transition of the aromatic carboxylate ligand. In addition to the broad band noted above, a weak band assigned to the $-\mathrm{NO}_{2}$ group $\mathrm{n}-\pi^{*}$ transition with admixture of ILCT is evident in the $350-450 \mathrm{~nm}$ region (Fig. S7 in ESI $\dagger$ ). ${ }^{7 \mathrm{c}} \mathrm{A}$ series of sharp lines that are assignable to transitions between the lanthanide ${ }^{7} \mathrm{~F}_{5}$ and ${ }^{5} \mathrm{G}_{6},{ }^{5} \mathrm{~L}_{10}$ and ${ }^{5} \mathrm{~L}_{9}$ levels are also observed in the excitation spectra of all of the complexes. ${ }^{6 \mathrm{~d}, 6 \mathrm{e}}$ The foregoing transitions are less intense than the absorptions due to the organic ligands and are overlapped by a broad excitation band. In turn, this proves that luminescence sensitization via ligand excitation is considerably more efficient than the direct excitation of the $\mathrm{Tb}^{3+}$ absorption level. The room-temperature emission spectra of the $\mathrm{Tb}^{3+}$ complexes exhibit the characteristic emission bands for $\mathrm{Tb}^{3+}$ and are centered at 490, 545, 585, and $620 \mathrm{~nm}$ as shown in 


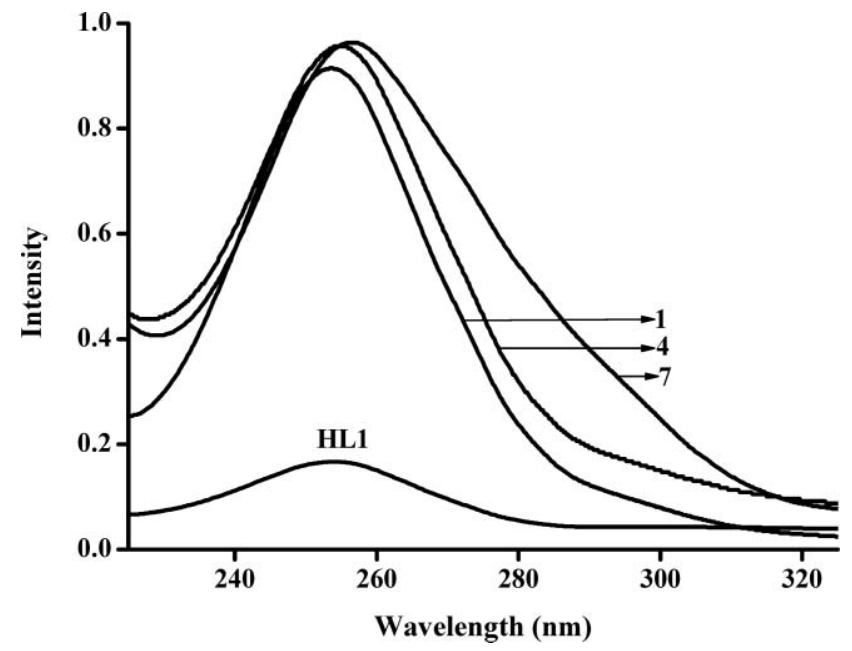

Fig. 5 UV-Visible absorption spectra of 4-benzyloxy benzoic acid and complexes $\mathbf{1}, \mathbf{4}$ and 7 in $\mathrm{CH}_{3} \mathrm{CN}$ solution $\left(2 \times 10^{-5} \mathrm{M}\right)$.

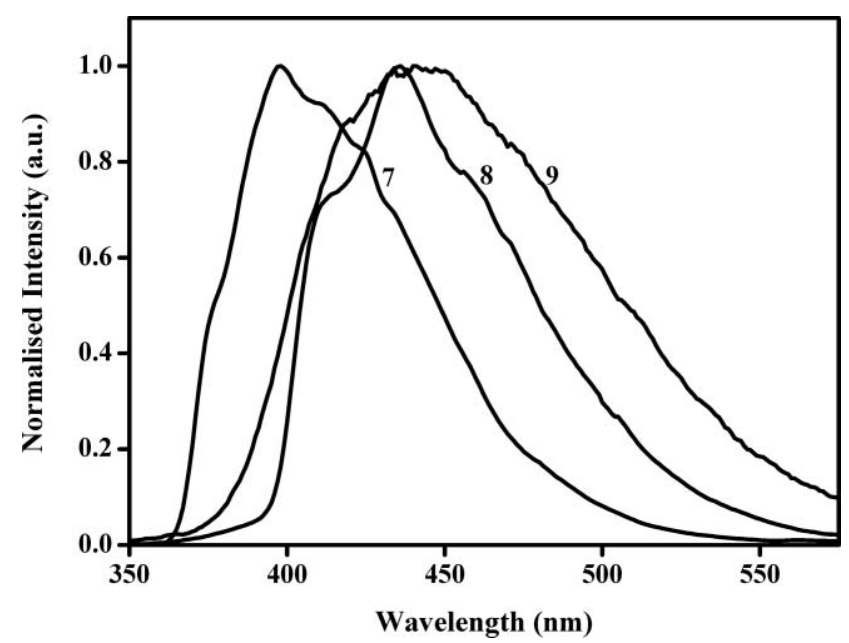

Fig. 6 Phosphorescence spectra of gadolinium complexes 7, 8 and 9 at $77 \mathrm{~K}$.

Figs. 7-9. These emissions result from deactivation of the ${ }^{5} \mathrm{D}_{4}$ excited state to the corresponding ground state ${ }^{7} \mathrm{~F}_{J}(J=6,5,4,3)$ of the $\mathrm{Tb}^{3+}$ ion. ${ }^{19 \mathrm{~d}, 20}$ In addition to the above sharp emission bands mentioned above, in the case of complex 3 a residual emission due to the HL3 ligand was detected in the $400-450 \mathrm{~nm}$ region thus implying that 3-nitro-4-benzyloxy benzoic acid is a poor sensitizer for $\mathrm{Tb}^{3+}$. The most intense emission is centered at $545 \mathrm{~nm}$ and corresponds to the hypersensitive transition ${ }^{5} \mathrm{D}_{4} \rightarrow{ }^{7} \mathrm{~F}_{5}$.

The excitation spectrum of $\mathrm{Eu}^{3+}$ complex 4 (Fig. S8 in ESI $\dagger$ ) exhibits broad and weak contributions from the ligand in the 250$350 \mathrm{~nm}$ region ( $\pi-\pi^{*}$ transition) along with a series of sharp lines that are characteristic of the $\mathrm{Eu}^{3+}$ energy-level structure. Such lines are most reasonably assigned to transitions between the ${ }^{7} \mathrm{~F}_{0,1}$ and the ${ }^{5} \mathrm{~L}_{6}$ and ${ }^{5} \mathrm{D}_{2,1}$ levels, ${ }^{20,21}$ thereby suggesting that luminescence sensitization of the $\mathrm{Eu}^{3+}$ complex via excitation of the ligand is not efficient in the case of 4 . On the other hand, the broad band observed between 250 and $350 \mathrm{~nm}$ in the excitation spectrum of complex 5 can be assigned to the $\pi-\pi^{*}$ transition of the aromatic carboxylate ligand HL2 (Fig. S9 in ESI $\dagger$ ). Furthermore, several narrow bands of lower intensity compared with those of complex 4

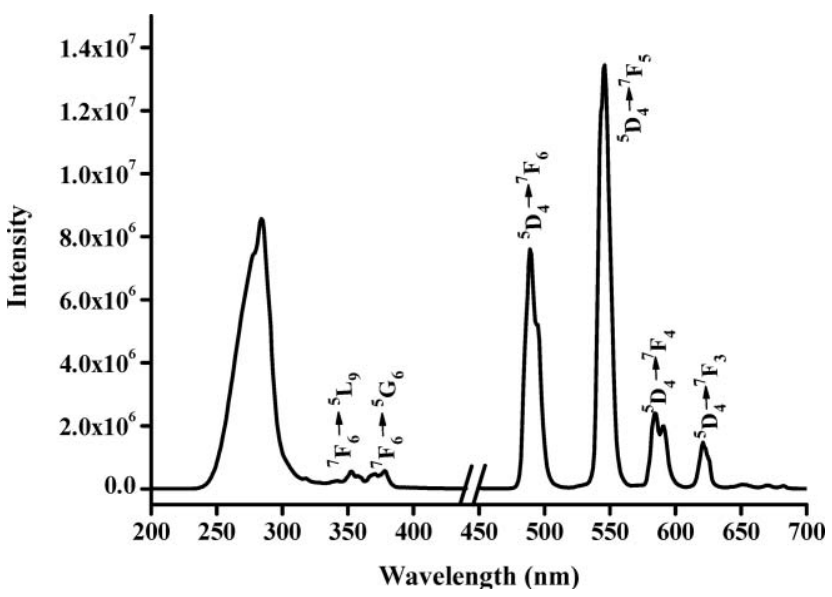

Fig. 7 Room-temperature excitation and emission spectra for complex 1 $\left(\lambda_{\mathrm{ex}}=285 \mathrm{~nm}\right)$ with emission monitored at approximately $545 \mathrm{~nm}$.

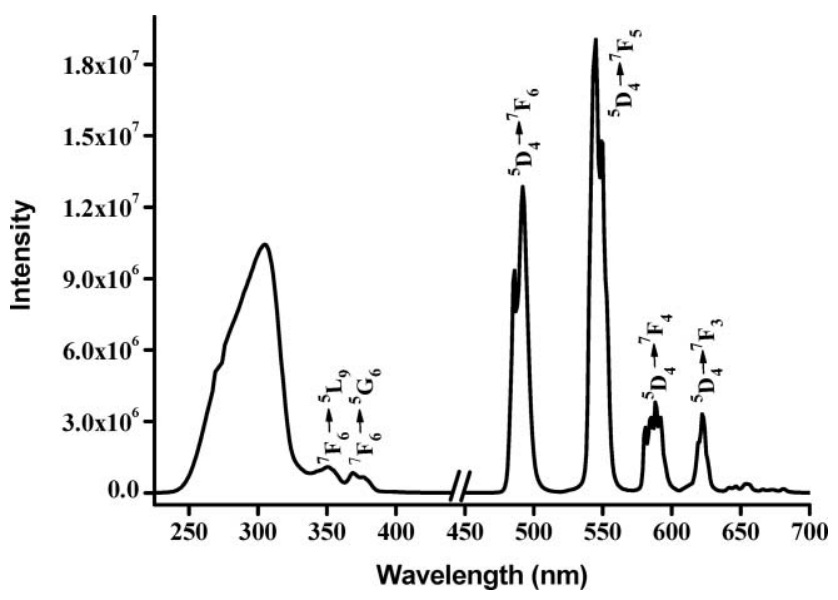

Fig. 8 Room-temperature excitation and emission spectra for complex 2 $\left(\lambda_{\mathrm{ex}}=305 \mathrm{~nm}\right)$ with emission monitored at approximately $545 \mathrm{~nm}$.

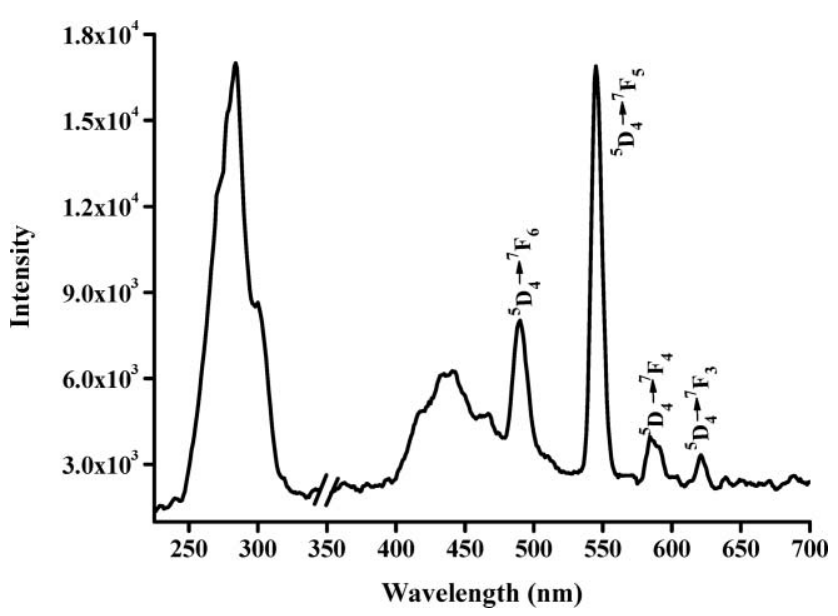

Fig. 9 Room-temperature excitation and emission spectra for complex 3 $\left(\lambda_{\mathrm{ex}}=284 \mathrm{~nm}\right)$ with emission monitored at approximately $545 \mathrm{~nm}$.

were also observed and can be assigned to $4 \mathrm{f}^{6}$-intraconfigurational transitions from the ground state to the excited state of the $\mathrm{Eu}^{3+}$ ion. A somewhat more intense band assigned to a nitro group $n-\pi^{*}$ transition with admixture of ILCT was detected in the 
350-425 nm region of the excitation spectrum of $\mathrm{Eu}^{3+}$ - 3-nitro4-benzyloxy benzoic acid (6) (Fig. S10 in ESI $\dagger$ ). ${ }^{7 \mathrm{c}}$ Additionally, a weak, broad band in the region $250-350 \mathrm{~nm}$ due to a $\pi-\pi^{*}$ transition of the ligand was evident in the excitation spectrum of 6. The room-temperature emission spectra of the $\mathrm{Eu}^{3+}$ complexes 4-6 (Fig. S8-10 in ESI $\dagger$ ) are characteristic of this metal in the 550$700 \mathrm{~nm}$ region, and comprise the well-resolved transitions that are anticipated from the metal-centered ${ }^{5} \mathrm{D}_{0}$ excited state to the ${ }^{7} \mathrm{~F}_{J}$ ground-state multiplet. Maximum intensities at 580, 593, 617, 652 and $694 \mathrm{~nm}$, respectively, were observed for the $J=0,1$, 2, 3 and 4 transitions, and the $J=2$ so-called "hypersensitive" transition is extremely intense. ${ }^{21}$ The intensity of the ${ }^{5} \mathrm{D}_{0} \rightarrow{ }^{7} \mathrm{~F}_{2}$ transition (electric dipole) is stronger than that of the ${ }^{5} \mathrm{D}_{0} \rightarrow{ }^{7} \mathrm{~F}_{1}$ transition (magnetic dipole), which implies that the coordination environment of the $\mathrm{Eu}^{3+}$ ion is asymmetric.

The luminescent lifetimes of $\mathrm{Ln}^{3+}$ complexes 1-6 were measured at both ambient temperature $(298 \mathrm{~K})$ and low temperature $(77 \mathrm{~K})$ on the basis of the respective luminescent decay profiles by fitting with monoexponential decay curves (Figs. 10-11 and Fig. S11 in ESI $\dagger$ ). Collectively, these data indicate the existence of a single chemical environment around the $\mathrm{Ln}^{3+}$ ion in each case.The pertinent values are summarized in Table 3 . Longer ${ }^{5} \mathrm{D}_{4}$ lifetime values have been observed for all the $\mathrm{Tb}^{3+}$ complexes (1-3) even in the presence of solvent molecules in the first coordination sphere, as they are essential vibrational deactivators of the excited states of $\mathrm{Ln}^{3+}$ ions. The somewhat shorter ${ }^{5} \mathrm{D}_{0}$ lifetime values that were observed for the $\mathrm{Eu}^{3+}$ analogues may be due to the dominant non-radiative decay channels associated with vibronic coupling because of the presence of solvent molecules. Similar observations have been made for several europium complexes. The energy gap between the luminescent state and the ground state manifold is approximately $12000 \mathrm{~cm}^{-1}$ for $\mathrm{Eu}^{3+}$ and $14800 \mathrm{~cm}^{-1}$ for $\mathrm{Tb}^{3+}$. Relatively efficient coupling of the $\mathrm{Eu}^{3+}$ excited states occurs to the third vibrational overtone of the proximate $\mathrm{OH}$ oscillators $\left(\mathrm{v}_{\mathrm{OH}}\right.$ $3300-3500 \mathrm{~cm}^{-1}$ ), and to the fourth harmonic in the case of $\mathrm{Tb}^{3+}$, which is consistent with the less efficient quenching observed for $\mathrm{Tb}^{3+}$ where the Franck-Condon overlap factor is less favorable..$^{22}$

In order to quantify the influence of the electron-releasing (-OMe) or electron-withdrawing $\left(-\mathrm{NO}_{2}\right)$ groups on the luminescence efficiency of $\mathrm{Ln}^{3+}$ complexes 1-6, the overall quantum yields $\left(\Phi_{\text {overall }}\right)$, radiative $\left(A_{R A D}\right)$ and nonradiative $\left(A_{N R}\right)$ decay rates, intrinsic quantum yields $\left(\Phi_{\mathrm{Ln}}\right)$ and energy transfer efficiencies $\left(\Phi_{\text {sen }}\right)$ have been calculated and are presented in Table 3 (see the ESI $\dagger$ for the procedures employed). The results indicate that the incorporation of an electron-releasing methoxy group in 4-benzyloxy benzoic acid enhances the $\pi$-electronic density of the ligand and consequently decreases the energy of the triplet level of HL2 to $24813 \mathrm{~cm}^{-1}$. It is well recognized that the energy-level

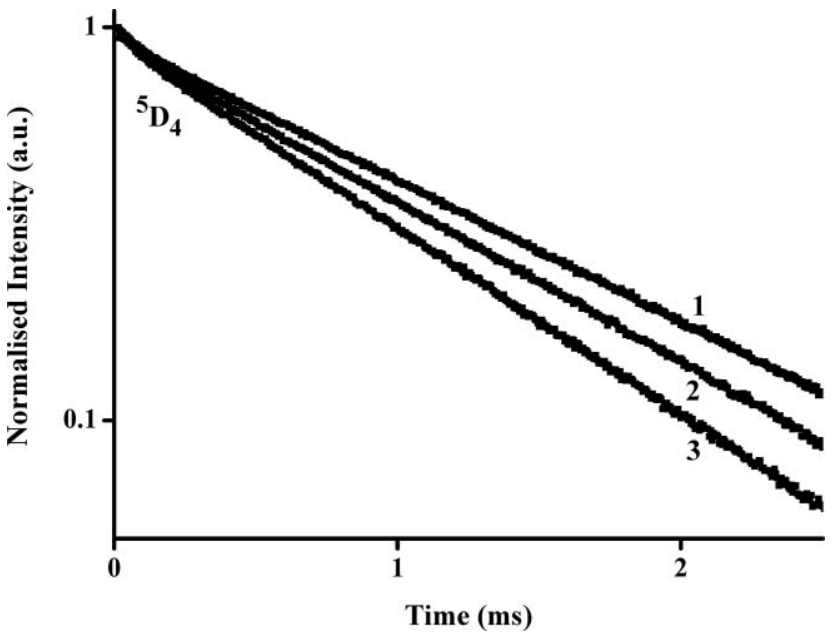

Fig. 10 Luminescence decay profiles for complexes 1, 2 and 3 excited at 285,305 and $284 \mathrm{~nm}$, respectively and monitored at $\sim 545 \mathrm{~nm}$.

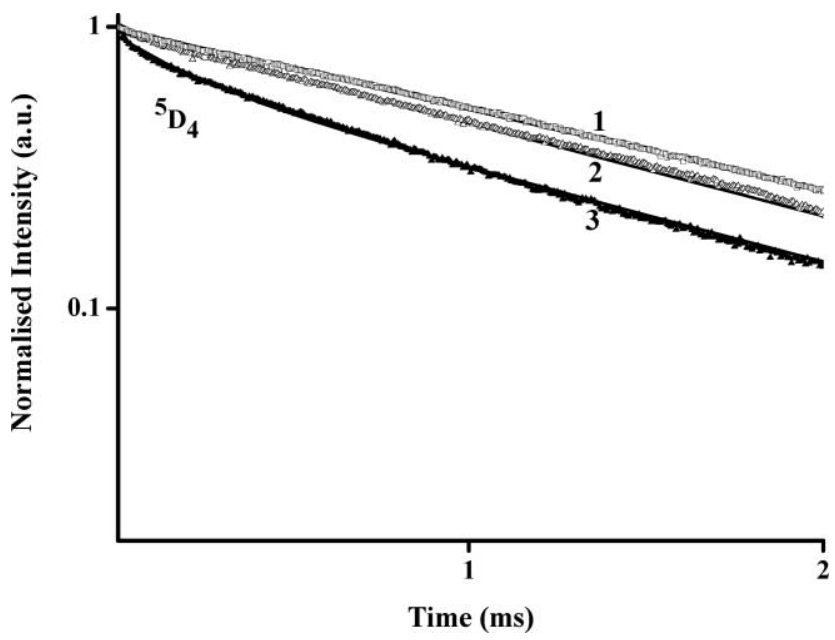

Fig. 11 Low-temperature luminescence decay profiles for complexes 1, $\mathbf{2}$ and $\mathbf{3}$ excited at 285, 305 and $284 \mathrm{~nm}$, respectively and monitored at $\sim 545 \mathrm{~nm}$.

match between the triplet states of the ligands to the ${ }^{5} \mathrm{D}_{\mathrm{J}}$ state of the $\mathrm{Ln}^{3+}$ cation is one of the key factors that governs the luminescence efficiency of $\mathrm{Ln}^{3+}$ complexes. Latva's empirical rule states that an optimal ligand-to-metal energy transfer process for $\mathrm{Ln}^{3+}$ requires $\Delta E\left({ }^{3} \pi \pi^{*}{ }_{-}^{5} \mathrm{D}_{4}\right)=2500-4500 \mathrm{~cm}^{-1}$ for $\mathrm{Tb}^{3+}$ and 2500 $4000 \mathrm{~cm}^{-1}$ for $\mathrm{Eu}^{3+} \cdot{ }^{23}$ On this basis it can be concluded that the energy transfer to the $\mathrm{Tb}^{3+}$ cation will be more effective for ligand HL2 than ligand HL1, since $\Delta E\left({ }^{3} \pi \pi^{*}{ }^{5} \mathrm{D}_{4}\right)$ for $\mathbf{1}$ and $\mathbf{2}$ are 5678 and $4313 \mathrm{~cm}^{-1}$, respectively. According to Reinhoudt's empirical

Table 3 Radiative $\left(A_{\mathrm{RAD}}\right)$ and nonradiative $\left(A_{\mathrm{NR}}\right)$ decay rates, ${ }^{5} \mathrm{D}_{0} /{ }^{5} \mathrm{D}_{4}$ lifetimes $\left(\tau_{\mathrm{obs}}\right)$, radiative lifetime $\left(\tau_{\mathrm{RAD}}\right)$, intrinsic quantum yields $\left(\Phi_{\mathrm{Ln}}\right)$, energy transfer efficiencies $\left(\Phi_{\text {sen }}\right)$, and overall quantum yields $\left(\Phi_{\text {overall }}\right)$ for complexes 1-6

\begin{tabular}{|c|c|c|c|c|c|c|c|}
\hline Compound & $A_{\mathrm{RAD}} / \mathrm{s}^{-1}$ & $A_{\mathrm{NR}} / \mathrm{s}^{-1}$ & $\tau_{\mathrm{obs}} / \mu \mathrm{s}$ & $\tau_{\mathrm{RAD}} / \mu \mathrm{s}$ & $\Phi_{\mathrm{Ln}}(\%)$ & $\Phi_{\text {sen }}(\%)$ & $\Phi_{\text {overall }}(\%)$ \\
\hline 2 & & & $1240 \pm 10$ & $1340 \pm 10$ & 93 & 35 & $33 \pm 3$ \\
\hline 4 & 363 & 2014 & $420 \pm 30$ & $2750 \pm 30$ & 15 & 0.90 & $0.14 \pm 0.01$ \\
\hline 5 & 622 & 1852 & $400 \pm 30$ & $1600 \pm 30$ & 25 & 1.90 & $0.49 \pm 0.05$ \\
\hline 6 & 633 & 2004 & $380 \pm 20$ & $1570 \pm 20$ & 24 & 0.17 & $0.04 \pm 0.01$ \\
\hline
\end{tabular}


rule, the intersystem crossing process becomes effective when $\Delta E$ $\left({ }^{1} \pi \pi^{*}{ }_{-}^{3} \pi \pi^{*}\right)$ is at least $5000 \mathrm{~cm}^{-1} .{ }^{24}$ The energy gaps $\Delta E\left({ }^{1} \pi \pi^{*}{ }_{-}^{3} \pi \pi^{*}\right)$ for ligands HL1 and HL2 are 6395 and $4426 \mathrm{~cm}^{-1}$, respectively. As a consequence, the intersystem crossing processes are effective for both of these ligands. The substantial contribution of the electron-releasing methoxy substituent to the overall sensitization of the $\mathrm{Tb}^{3+}$-centered luminescence in $\mathbf{2}$ is confirmed by (i) an increase in the intrinsic quantum yield (77\% for $\mathbf{1}$ and $93 \%$ for 2) and (ii) the significant enhancement of $\Phi_{\text {sen }}$ from 13 to $35 \%$. This represents a three-fold enhancement in the overall quantum yield for $\mathbf{2}$ in comparison with that for $\mathbf{1}$. On the other hand, the presence of the nitro electron-withdrawing group in 3-nitro-4benzyloxy benzoic acid (HL3) dramatically decreases the overall sensitization efficiency of the $\mathrm{Tb}^{3+}$-centered luminescence, even though the triplet energy level of this ligand $\left(24937 \mathrm{~cm}^{-1}\right)$ is well above the emitting level of that of the metal ion. In complex 3, this is due to dissipation of the excitation energy through the $\pi^{*}$-n transition of the nitro group along with participation of the ILCT bands. Poor luminescence efficiency $\left(\Phi_{\text {overall }}=0.1\right.$ $0.5 \%$ ) is also apparent in complexes $\mathbf{4 - 6}$, and may be due to the weak sensitization efficiencies $\left(\Phi_{\text {sen }}=0.9-1.9 \%\right)$ of HL1-HL3 with respect to the $\mathrm{Eu}^{3+}$ ion. The latter observation can be explained on the basis of the large energy gap between the triplet states of the ligands ( 7500 to $8800 \mathrm{~cm}^{-1}$ ) and the ${ }^{5} \mathrm{D}_{0}$ emitting level of the $\mathrm{Eu}^{3+}$ ion $\left(17300 \mathrm{~cm}^{-1}\right)$.

\section{Conclusions}

A new class of $\mathrm{Eu}^{3+}$ and $\mathrm{Tb}^{3+}$ complexes has been synthesized based on the use of 3-methoxy-4-benzyloxy benzoic acid or 3nitro-4-benzyloxy benzoic acid as the supporting ligand. The new complexes have been characterized by a variety of spectroscopic techniques and two of the $\mathrm{Tb}^{3+}$ complexes have been structurally authenticated by single-crystal X-ray diffraction. The X-ray crystal structures reveal that the new terbium complexes are dimeric in nature, in contrast to the majority of known lanthanide benzoic acid complexes which exist as one-dimensional polymers. Another noteworthy feature of the new complexes relates to the existence of three different types of benzoato binding modes, viz. bridging bidentate, chelating and monodentate. Scrutiny of the singlecrystal X-ray data also revealed the existence of an interesting one-dimensional array, which is held together by intermolecular hydrogen-bonding and $\mathrm{C}-\mathrm{H}-\pi$ interactions. The present study has also revealed that the presence of electron-releasing or electronwithdrawing groups on position 3 of the 4-benzyloxy benzoic acid ligand has a profound effect on the $\pi$-electron density of the ligands and consequently on the photosensitization of $\mathrm{Ln}^{3+}$ ions. Specifically, the presence of a methoxy substituent in this position results in a significant improvement in the photoluminescence efficiency of the $\mathrm{Tb}^{3+}-3$-methoxy-4-benzyloxy benzoate complex in comparison with that of the 4-benzyloxy benzoate complex $(10-33 \%)$. By contrast, the introduction of a nitro group in the 3 position dramatically diminishes the photoluminescence efficiency of the $\mathrm{Tb}^{3+}$-3-nitro-4-benzyloxy benzoate complex due to the presence of a channel that permits dissipation of the excitation energy via the $\pi^{*}$-n transition of the nitro group in conjunction with the ILCT band. Given the substantial energy gaps between the triplet states of the various benzoate ligands and the emissive level of $\mathrm{Eu}^{3+}$, it is not surprising that the $\mathrm{Eu}^{3+}$ benzoates exhibit poor luminescence intensities.

\section{Experimental}

\section{Materials}

The following chemicals were procured commercially and used without further purification: terbium(III) nitrate hexahydrate 99.9\% (Across Organics), europium(III) nitrate hexahydrate, 99.9\% (Across Organics); gadolinium(III) nitrate hexahydrate (Treibacher); 4-hydroxy benzoic acid, 99\% (Aldrich); 4-hydroxy3-nitrobenzoic acid, 99\% (Aldrich); 4-hydroxy-3-methoxy benzoic acid, 99\% (Aldrich); benzyl bromide, 99.9\% (Aldrich). All the other chemicals used were of analytical reagent grade.

\section{Physical measurements}

Elemental analyses were performed with a Perkin-Elmer Series 2 Elemental Analyzer 2400. A Perkin-Elmer Spectrum One FTIR spectrometer using $\mathrm{KBr}$ (neat) was used to obtain the IR spectral data and a Bruker $500 \mathrm{MHz}$ NMR spectrometer was used to record the ${ }^{1} \mathrm{H}$ NMR and ${ }^{13} \mathrm{C}$ NMR spectra of the ligands in $\mathrm{CDCl}_{3}$ solution. The mass spectra were recorded on a JEOL JSM 600 fast atom bombardment (FAB) high resolution mass spectrometer (FABMS) and the thermogravimetric analyses were performed on a TGA- 50H instrument (Shimadzu, Japan). The absorbances of the ligands were measured in $\mathrm{CH}_{3} \mathrm{CN}$ solution on a UV-vis spectrophotometer (Shimadzu, UV-2450) and the photoluminescence (PL) spectra were recorded on a Spex-Fluorolog FL22 spectrofluorimeter equipped with a double grating $0.22 \mathrm{~m}$ Spex 1680 monochromator and a $450 \mathrm{~W}$ Xe lamp as the excitation source operating in the front face mode. The lifetime measurements were carried out at room temperature using a Spex 1040D phosphorimeter. The diffuse reflectance spectra of the new lanthanide complexes and the standard phosphor were recorded on a Shimadzu, UV-2450 UV-vis spectrophotometer using $\mathrm{BaSO}_{4}$ as a reference. The overall quantum yields $\left(\Phi_{\text {overall }}\right)$, were measured at room temperature using the technique for powdered samples described by Bril et al. ${ }^{25}$ along with the following expression:

$$
\Phi_{\text {overall }}=\left(\frac{1-\mathrm{r}_{\mathrm{st}}}{1-\mathrm{r}_{\mathrm{x}}}\right)\left(\frac{\mathrm{A}_{\mathrm{x}}}{\mathrm{A}_{\mathrm{st}}}\right) \Phi_{\mathrm{st}}
$$

where $r_{\mathrm{x}}$ and $r_{\mathrm{st}}$ represent the diffuse reflectance of the complexes and of the standard phosphor, respectively (with respect to a fixed wavelength), and $\Phi_{\mathrm{st}}$ is the quantum yield of the standard phosphor. The terms $A_{\mathrm{x}}$ and $A_{\mathrm{st}}$ represent the areas under the complex and the standard emission spectra, respectively. To acquire absolute intensity values, $\mathrm{BaSO}_{4}$ was used as a reflecting standard. Sodium salicylate (Merck) was employed as the standard phosphor, the emission spectrum of which comprises an intense broad band with a maximum at approximately $425 \mathrm{~nm}$, and a constant $\Phi$ value $(60 \%)$ for excitation wavelengths between 220 and $380 \mathrm{~nm}$. Three measurements were carried out for each sample, and the reported $\Phi_{\text {overall }}$ value corresponds to the arithmetic mean value of the three values. The errors in the quantum yield values associated with this technique were estimated to be $\pm 10 \% .{ }^{25}$ 
The X-ray diffraction data were collected at $153 \mathrm{~K}$ on a Nonius Kappa CCD diffractometer equipped with an Oxford Cryostream low-temperature device and a graphite-monochromated Mo $\mathrm{K} \alpha$ radiation source $(\lambda=0.71073 \AA)$. Corrections were applied for Lorentz and polarization effects. ${ }^{26}$ All of the structures were solved by direct methods and refined by full-matrix least-squares cycles on $F^{2}$. All of the nonhydrogen atoms were allowed anisotropic thermal motion, and the hydrogen atoms were placed in fixed, calculated positions using a riding model (C-H, $0.96 \AA$ ). Selected crystal data and data collection and refinement parameters are listed in Table 1. CCDC 729140 for $\mathbf{1}$ and CCDC 734105 for $\mathbf{2}$.

\section{Synthesis of HL1}

Methyl-4-hydroxy benzoate. 4-hydroxy benzoic acid (2 g, $14.4 \mathrm{mmol}$ ) was dissolved in $50 \mathrm{~mL}$ of $\mathrm{CH}_{3} \mathrm{OH}$ and $2 \mathrm{~mL}$ of conc. $\mathrm{H}_{2} \mathrm{SO}_{4}$ was added. The reaction mixture was refluxed overnight. The excess methanol was evaporated off and the reaction mixture was poured onto ice cold water. Methyl-4-hydroxy benzoate was isolated as a white powder. Yield, $1.1 \mathrm{~g}(50 \%)$. ${ }^{1} \mathrm{H}$ NMR (500 $\mathrm{MHz}): \delta$ (ppm) 7.877-7.894 (d, 2H), 6.908-6.926 (d, 2H), 3.822 (s, 3H). ${ }^{13} \mathrm{C} \mathrm{NMR} \mathrm{(500} \mathrm{MHz,} \mathrm{CDCl}_{3}$ ): $\delta$ (ppm) 167.57, 160.65, $131.94,121.97,115.34,52.09 . m / z=153.24(\mathrm{M}+\mathrm{H})^{+}$. FT-IR $(\mathrm{KBr})$ $v_{\max }: 3311,1682,1607,1588,1514,1434,1314,1279,1164,849$, $771 \mathrm{~cm}^{-1}$.

Methyl-4-benzyloxy benzoate. Potassium carbonate $(0.34 \mathrm{~g}$, $2.46 \mathrm{mmol})$ was added to a solution of methyl-4-hydroxy benzoate $(0.25 \mathrm{~g}, 1.6 \mathrm{mmol})$ in freshly distilled DMF $(50 \mathrm{~mL})$. The resulting mixture was refluxed for $30 \mathrm{~min}$, following which benzyl bromide $(0.28 \mathrm{~g}, 1.64 \mathrm{mmol})$ was added and the solution was refluxed further at $78{ }^{\circ} \mathrm{C}$ for $48 \mathrm{~h}$. The resulting mixture was poured onto water and the precipitate was filtered off, washed with water and dried. Yield, $0.225 \mathrm{~g}(56.72 \%):{ }^{1} \mathrm{H}$ NMR (500 MHz): $\delta(\mathrm{ppm})$ 8.000-7.443 (d, 2H), 7.443- 7.265 (d, 5H), 6.986-7.004 (d, 2H), 5.12 (s, 2H), 3.88 (s, 3H).${ }^{13} \mathrm{C} \mathrm{NMR}\left(500 \mathrm{MHz}, \mathrm{CDCl}_{3}\right.$ ): $\delta$ (ppm) 166.84, $162.48,136.25,131.62,128.69,128.22,127.50,122.83,114.46$, 70.10, 51.89. $m / z=243.44(\mathrm{M}+\mathrm{H})^{+}$. FT-IR $(\mathrm{KBr}) \mathrm{v}_{\max }: 3402$, $1715,1604,1510,1438,1318,1276,1170,1010,852,771 \mathrm{~cm}^{-1}$.

4-Benzyloxy benzoic acid (HL1). Methyl-4-benzyloxy benzoate $(0.1 \mathrm{~g}, 0.413 \mathrm{mmol})$ was refluxed for $4 \mathrm{~h}$ with $\mathrm{KOH}(0.069 \mathrm{~g}$, $1.23 \mathrm{mmol}$ ) in $50 \mathrm{~mL}$ of ethanol. The reaction mixture was poured into ice cold water, acidified with dilute $\mathrm{HCl}$, and the precipitate was filtered, washed, dried and recrystallized from $\mathrm{CHCl}_{3}$. Yield, $0.07 \mathrm{~g}(74 \%):{ }^{1} \mathrm{H}$ NMR $(500 \mathrm{MHz}): \delta(\mathrm{ppm}) 7.422-$ $7.451(\mathrm{~d}, 2 \mathrm{H}), 7.260-7.420(\mathrm{~m}, 5 \mathrm{H}), 7.06-7.034(\mathrm{~d}, 2 \mathrm{H}), 5.143(\mathrm{~s}$, $2 \mathrm{H}) .{ }^{13} \mathrm{C} \mathrm{NMR}\left(500 \mathrm{MHz}, \mathrm{CDCl}_{3}\right): \delta(\mathrm{ppm}) 167.32,162.27,131.86$, $129.45,128.84,128.36,128.15,123.49,114.97,69.80 . \mathrm{m} / \mathrm{z}=229.24$ $(\mathrm{M}+\mathrm{H})^{+}$. Elemental analysis (\%): Calcd for $\mathrm{C}_{14} \mathrm{H}_{12} \mathrm{O}_{3}(228.23)$ : C, 73.67; H, 5.30. Found: C, 73.35; H, 5.27. FT-IR (KBr) $v_{\max }: 3447$, $1686,1607,1579,1513,1454,1430,1304,1258,738,693 \mathrm{~cm}^{-1}$.

\section{Synthesis of HL2}

Methyl-3-methoxy-4-hydroxy benzoate. This compound was synthesized as described in procedure a. Yield, $1.15 \mathrm{~g}(57.2 \%)$ : ${ }^{1} \mathrm{H}$ NMR (500 MHz): $\delta(\mathrm{ppm}) 7.593-7.582(\mathrm{~d}, 1 \mathrm{H}), 6.953$ (s, 1H), 6.916-6.926 (d, IH) 3.927 (s, 3H), 3.862 (s, 3H). ${ }^{13} \mathrm{C}$ NMR $\left(500 \mathrm{MHz}, \mathrm{CDCl}_{3}\right): \delta(\mathrm{ppm}) 166.97,150.09,146.23,124.17$, $122.17,114.15,111.78,56.07,51.99 . m / z=182.36(\mathrm{M})^{+}$. FT-IR
$(\mathrm{KBr}) v_{\max }: 3534,1694,1601,1531,1435,1329,1285,1122,1031$, $868,762 \mathrm{~cm}^{-1}$.

Methyl-3-methoxy-4-benzyloxy benzoate. This compound was synthesized as described in procedure b. Yield, $0.25 \mathrm{~g}(55.7 \%)$ : ${ }^{1} \mathrm{H}$ NMR (500 MHz): $\delta$ (ppm) 7.596-7.625 (d, 1H), 7.569 (s, 1H), 7.264-7.449 (m, 5H) 6.884-6.912 (d, 1H), $3.92(\mathrm{~s}, 3 \mathrm{H}), 3.88$ $(\mathrm{s}, 3 \mathrm{H}) .{ }^{13} \mathrm{C} \mathrm{NMR}\left(500 \mathrm{MHz}, \mathrm{CDCl}_{3}\right): \delta(\mathrm{ppm}) 166.87,152.08$, $149.10,136.34,128.66,128.08,127.23,123.37,122.96,112.42$, 70.77, 56.08, 52.00. $\mathrm{m} / z=273.31(\mathrm{M}+\mathrm{H})^{+}$. FT-IR $(\mathrm{KBr}) \mathrm{v}_{\max }$ : $3393,1709,1595,1515,1437,1345,1298,1132,992,855,747 \mathrm{~cm}^{-1}$.

3-methoxy-4-benzyloxy benzoic acid (HL2). This compound was synthesized as described in procedure c. Yield, $0.07 \mathrm{~g}(73 \%)$ : ${ }^{1} \mathrm{H}$ NMR (500 MHz): $\delta(\mathrm{ppm}) 7.662-7.666(\mathrm{~d}, 1 \mathrm{H}), 7.598(\mathrm{~s}, 1 \mathrm{H})$, 7.253-7.594 (m, 5H), 6.904-6.921 (d, 1H), $7.25(\mathrm{~s}, 1 \mathrm{H}), 6.91(\mathrm{~d}$, $1 \mathrm{H}), 5.22(\mathrm{~s}, 2 \mathrm{H}), 3.93(\mathrm{~s}, 3 \mathrm{H}) .{ }^{13} \mathrm{C} \mathrm{NMR}\left(500 \mathrm{MHz}, \mathrm{CDCl}_{3}\right)$ : $\delta(\mathrm{ppm}) 165.94,155.65,136.64,136.03,129.52,128.39,127.39$, $124.15,116.13,70.0 . m / z=259.64(\mathrm{M}+\mathrm{H})^{+}$. Elemental analysis (\%): Calcd for $\mathrm{C}_{15} \mathrm{H}_{14} \mathrm{O}_{4}$ (258.23): C, 69.06; H, 5.46. Found: C, 68.88; H, 5.11. FT-IR (KBr) $v_{\max }: 2912,1678,1600,1519,1454$, $1427,1349,1277,1026,761 \mathrm{~cm}^{-1}$.

\section{Synthesis of HL3}

Methyl-3-nitro-4-hydroxy benzoate. This compound was synthesized as described in procedure a. Yield, $1.3 \mathrm{~g}(60.4 \%):{ }^{1} \mathrm{H}$ NMR (500 MHz): $\delta(\mathrm{ppm}) 8.831(\mathrm{~s}, 1 \mathrm{H}), 8.252-8.259(\mathrm{~d}, 1 \mathrm{H})$, 7.264-7.241 (d, 1H), 3.94 (s, 3H). ${ }^{13} \mathrm{C} \mathrm{NMR}\left(500 \mathrm{MHz}, \mathrm{CDCl}_{3}\right)$ : $\delta$ (ppm) 164.76, 158.08, 137.90, 133.21, 127.33, 122.74, 120.25, 52.57. $m / z=197.11(\mathrm{M})^{+}$. FT-IR $(\mathrm{KBr}) \mathrm{v}_{\max }: 3260,1719,1624$, $1539,1438,1288,1166,910,760 \mathrm{~cm}^{-1}$.

Methyl-3-nitro-4-benzyloxy benzoate. This compound was synthesized as described in procedure b. Yield, $0.24 \mathrm{~g}(54.9 \%)$ : ${ }^{1} \mathrm{H}$ NMR (500 MHz): $\delta(\mathrm{ppm}) 8.188(\mathrm{~s}, 1 \mathrm{H}), 8.166-8.171(\mathrm{~d}, 1 \mathrm{H})$, 7.262-7.463 (m, 5H), 7.176-7.262 (d, 1H), $7.16(\mathrm{D}, 14 \mathrm{H}), 5.31(\mathrm{~s}$, 2H), 3.92 (s, 3H). ${ }^{13} \mathrm{C} \mathrm{NMR} \mathrm{(500} \mathrm{MHz,} \mathrm{CDCl}_{3}$ ): $\delta$ (ppm) 164.91, $155.05,139.70,135.15,134.76,128.84,128.51,127.26,126.97$, $122.75,114.49,71.37,52.50 . \mathrm{m} / z=288.38(\mathrm{M}+\mathrm{H})^{+}$. FT-IR $(\mathrm{KBr})$ $v_{\max }: 3448,1709,1613,1541,1430,1262,1127,1023,727 \mathrm{~cm}^{-1}$.

3-nitro-4-benzyloxy benzoic acid (HL3). This compound was synthesized as described in procedure c. Yield, $0.066 \mathrm{~g}(69 \%)$ : ${ }^{1} \mathrm{H}$ NMR (500 MHz): $\delta(\mathrm{ppm}) 8.576(\mathrm{~s}, 1 \mathrm{H}), 8.208-8.212(\mathrm{~d}$, 1H), 7.263-7.469 (m, 5H), 7.185-7.203 (d,1H) $5.33(\mathrm{~s}, 2 \mathrm{H}) .{ }^{13} \mathrm{C}$ NMR (500 MHz, $\mathrm{CDCl}_{3}$ ): $\delta$ (ppm) 165.94, 155.65, 136.64, 136.03, $129.52,129.19,128.39,127.39,124.15,116.13,72.15 . \mathrm{m} / \mathrm{z}=273.43$ $(\mathrm{M})^{+}$. Elemental analysis (\%): Calcd for $\mathrm{C}_{14} \mathrm{H}_{11} \mathrm{NO}_{5}$ (273.21): C, 61.54; H, 4.06; N, 5.13. Found: C, 61.09; H, 3.97; N, 5.06. FT-IR $(\mathrm{KBr}) v_{\max }: 2870,1689,1614,1537,1492,1428,1269,1163,984$, $756 \mathrm{~cm}^{-1}$.

\section{Syntheses of lanthanide complexes}

In a typical procedure, an ethanolic solution of $\mathrm{Ln}\left(\mathrm{NO}_{3}\right)_{3} \cdot 6 \mathrm{H}_{2} \mathrm{O}$ $(0.5 \mathrm{mmol})(\mathrm{Ln}=\mathrm{Eu}, \mathrm{Tb}$, or $\mathrm{Gd})$ was added to a solution of the appropriate carboxylic acid $(1.5 \mathrm{mmol})$ in ethanol in the presence of $\mathrm{NaOH}(1.5 \mathrm{mmol})$. Precipitation took place immediately, and each reaction mixture was stirred subsequently for $10 \mathrm{~h}$ at room temperature. The crude product was filtered, washed with ethanol and dried. The resulting complexes were then purified 
by recrystallization from a dimethylsulfoxide/methanol solvent mixture. Single crystals of $\mathbf{1}$ and $\mathbf{2}$ suitable for X-ray study were obtained from a dimethylsulfoxide/methanol solvent mixture after storage for 5 weeks at ambient temperature.

$\mathbf{T b}_{\mathbf{2}}(\mathbf{L 1})_{6}(\mathrm{DMSO})_{2}\left(\mathrm{H}_{\mathbf{2}} \mathrm{O}\right)_{2}$ (1). Elemental analysis (\%): calcd for $\mathrm{C}_{88} \mathrm{H}_{82} \mathrm{~Tb}_{2} \mathrm{~S}_{2} \mathrm{O}_{22}$ (1873.50): C, 56.84; $\mathrm{H}, 4.56$. Found: C, 56.59; $\mathrm{H}, 4.27$. FT-IR (KBr) $v_{\max }: 3390,1610,1586,1519,1438,1380$, $1252,1176,1040,783 \mathrm{~cm}^{-1}$.

$\mathbf{T b}_{\mathbf{2}}(\mathbf{L 2})_{6}(\mathbf{M e O H})_{2}\left(\mathbf{H}_{2} \mathbf{O}\right)_{4}$ (2). Elemental analysis (\%): calcd for $\mathrm{C}_{92} \mathrm{H}_{94} \mathrm{~Tb}_{2} \mathrm{O}_{30}$ (1997.56): C, 54.97; H, 4.61. Found: C, 54.98; H, 4.69. FT-IR (KBr) $v_{\max }: 3560,1597,1530,1423,1264,1224,1186$, $1122,778 \mathrm{~cm}^{-1}$.

$\mathrm{Tb}_{2}(\mathbf{L 3})_{6}(\mathrm{DMSO})_{2}\left(\mathrm{H}_{2} \mathrm{O}\right)_{4}$ (3). Elemental analysis (\%): calcd for $\mathrm{C}_{88} \mathrm{H}_{80} \mathrm{~Tb}_{2} \mathrm{~S}_{2} \mathrm{O}_{36} \mathrm{~N}_{6}$ (2178.26): C, 48.49; $\mathrm{H}, 3.70 ; \mathrm{N}, 3.86$. Found: C, 48.11; H, 3.25; N, 3.91. FT-IR (KBr) $v_{\max }: 3417,1614,1588$, $1531,1423,1399,1349,1279,1045,924,781 \mathrm{~cm}^{-1}$.

$\mathbf{E u}_{2}(\mathbf{L 1})_{6}\left(\mathrm{H}_{2} \mathbf{O}\right)_{4}$ (4). Elemental analysis (\%): calcd for $\mathrm{C}_{84} \mathrm{H}_{74} \mathrm{Eu}_{2} \mathrm{O}_{22}$ (1740.31): C, 58.00; H, 4.29. Found: C, 57.93; H, 4.28. FT-IR (KBr) $v_{\max }: 3372,1608,1585,1537,1506,1432,1380$, $1251,1176,1105,782 \mathrm{~cm}^{-1}$.

$\mathbf{E u}_{2}(\mathbf{L 2})_{6}\left(\mathbf{C H}_{3} \mathbf{O H}\right)_{2}\left(\mathbf{H}_{2} \mathbf{O}\right)_{4}$ (5). Elemental analysis (\%): calcd for $\mathrm{C}_{92} \mathrm{H}_{94} \mathrm{Eu}_{2} \mathrm{O}_{30}$ (1984.43): C, 55.70; H, 4.78. Found: C, 55.14; H, 4.54. FT-IR (KBr) $v_{\max }: 3551,1599,1528,1454,1423,1396,1264$, $1224,1121,778 \mathrm{~cm}^{-1}$.

$\mathrm{Eu}_{2}(\mathbf{L 3})_{6}(\mathrm{DMSO})_{2}\left(\mathrm{H}_{2} \mathrm{O}\right)_{4}$ (6). Elemental analysis (\%): calcd for $\mathrm{C}_{88} \mathrm{H}_{80} \mathrm{Eu}_{2} \mathrm{~N}_{6} \mathrm{O}_{36} \mathrm{~S}_{2}(2166.25)$ : C, 48.80; H, 3.72; N, 3.88. Found: C, 49.06; H, 3.27; N,3.70. FT-IR (KBr) $v_{\max }: 3436,1608,1590$, $1536,1506,1434,1380,1251,1175,1040,783 \mathrm{~cm}^{-1}$.

$\mathbf{G d}_{\mathbf{2}}(\mathbf{L 1})_{6}(\mathbf{D M S O})_{\mathbf{2}}\left(\mathrm{H}_{\mathbf{2}} \mathrm{O}\right)_{\mathbf{4}} \mathbf{( 7 )}$. Elemental analysis (\%): calcd for $\mathrm{C}_{88} \mathrm{H}_{86} \mathrm{Gd}_{2} \mathrm{~S}_{2} \mathrm{O}_{24}$ (1906.34): C, 55.45; H, 4.55. Found: C, 55.32; H, 4.15. FT-IR (KBr) $v_{\max }: 3270,1610,1519,1434,1380,1252$, $1175,1045,845,782 \mathrm{~cm}^{-1}$.

$\mathbf{G d}_{2}\left(\mathbf{L 2}_{6}\right)_{6}(\mathrm{DMSO})_{2}\left(\mathrm{H}_{2} \mathrm{O}\right)_{4}(\mathbf{8})$. Elemental analysis (\%): calcd for $\mathrm{C}_{96} \mathrm{H}_{102} \mathrm{Gd}_{2} \mathrm{~S}_{2} \mathrm{O}_{30}$ (2114.44): C, 54.53; H, 4.86. Found: C, 54.34; H, 4.58. FT-IR (KBr) $v_{\max }: 3551,1599,1530,1454,1423,1396$, $1264,1224,1122,1036,778 \mathrm{~cm}^{-1}$.

$\mathbf{G d}_{2}(\mathbf{L 3})_{6}(\mathbf{D M S O})_{2}\left(\mathrm{H}_{2} \mathrm{O}\right)_{4}(\mathbf{9})$. Elemental analysis (\%): calcd for $\mathrm{C}_{88} \mathrm{H}_{80} \mathrm{Gd}_{2} \mathrm{~N}_{6} \mathrm{~S}_{2} \mathrm{O}_{36}(2176.25)$ : $\mathrm{C}, 48.57 ; \mathrm{H}, 3.71 ; \mathrm{N}, 3.86$. Found: C, 48.26; H, 3.40; N, 4.11. FT-IR (KBr) $v_{\max }: 3418,1615,1588$, $1532,1424,1350,1279,1149,1045,782 \mathrm{~cm}^{-1}$.

\section{Acknowledgements}

The authors acknowledge financial support from the Department of Science and Technology (SR/S1/IC- 36/20073) and Council of Scientific and Industrial Research (NWP0010). SSK thanks CSIR, New Delhi for the award of Junior Research Fellowship. A.H.C. thanks the Robert A. Welch Foundation (F-0003) for financial support.

\section{Notes and References}

1 (a) A. Picot, A. D’Aleo, P. L. Baldeck, A. Grichine, A. Duperray, C. Andraud and O. Maury, J. Am. Chem. Soc., 2008, 130, 1532; (b) D. Parker and J. A. G. Williams, The Lanthanides and Their Interrelation with Biosystems, M. Dekker, Inc., New York, 2003, Vol. 40, p. 233.
2 (a) E. Brunet, O. Juanes and J. C. Rodriguez-Ubis, Curr. Chem. Biol., 2007, 1, 11; (b) R. Shunmugam and G. N. Tew, Chem.-Eur. J., 2008, 14, 5409 .

3 (a) J.-C. G. Bünzli, Acc. Chem. Res., 2006, 39, 53; (b) S. Pandya, J. Yu and D. Parker, Dalton Trans., 2006, 2757; (c) T. Gunnlaugsson and J. P. Leonard, Chem. Commun., 2005, 3114; (d) D. Parker, Chem. Soc. Rev., 2004, 33, 156.

4 (a) J.-C. G. Bünzli and C. Piguet, Chem. Soc. Rev., 2005, 34, 1048; (b) A. de Bettencourt-Dias, Dalton Trans., 2007, 2229; (c) K. Kuriki, Y. Koike and Y. Okamoto, Chem. Rev., 2002, 102, 2347.

5 (a) J.-M. Lehn, Angew. Chem., Int. Ed. Engl., 1990, 29, 1304; (b) J. Kido and Y. Okamoto, Chem. Rev., 2002, 102, 2357; (c) J.-C. G. Bünzli and C. Piguet, Chem. Rev., 2002, 102, 1897; (d) D. Parker, Coord. Chem. Rev., 2000, 205, 109; (e) C. Piguet and J.-C. G. Bünzli, Chem. Soc. Rev., 1999, 28, 347; (f) S. Petoud, S. M. Cohen, J.-C. G. Bünzli and K. N. Raymond, J. Am. Chem. Soc., 2003, 125, 13324.

6 (a) M. Eddaudi, J. Kim, J. B. Wachter, H. K. Chae, M. O' Keeffe and O. M. Yaghi, J. Am. Chem. Soc., 2001, 123, 4368; (b) L. Pan, M. B. Sander, X. Huang, J. Li, M. Smith, E. Bittner, B. Bockrath and J. K. Johnson, J. Am. Chem. Soc., 2004, 126, 1308; (c) X. Y. Chen, Y. Bretonniere, J. Pecaut, D. Imbert, J.-C. G. Bünzli and M. Mazzanti, Inorg. Chem., 2007, 46, 625; (d) R. Shyni, S. Biju, M. L. P. Reddy, A. H. Cowley and M. Findlater, Inorg. Chem., 2007, 46, 11025; (e) S. Raphael, M. L. P. Reddy, A. H. Cowley and M. Findlater, Eur. J. Inorg. Chem., 2008, 4387.

7 (a) M. Hilder, P. C. Junk, U. H. Kynast and M. M. Lezhnina, J. Photochem. Photobiol., A, 2009, 202, 10; (b) R. Zhong, R. Zou, M. Du, L. Jiang, T. Yamada, G. Maruta, S. Takeda and Q. Xu, Cryst.Eng. Comm., 2008, 10, 605; (c) V. Tsaryuk, K. Zhuravlev, V. Zolin, P. Gawryszewska, J. Legendziewicz, V. Kudryashova and I. Pekareva, J. Photochem. Photobiol., A, 2006, 177, 314.

8 A. de Bettencourt-Dias and S. Viswanathan, Dalton Trans., 2006, 4093.

9 S. Viswanathan and A. de Bettencourt-Dias, Inorg. Chem., 2006, 45, 10138.

10 Y. Li, F. K. Zheng, X. Liu, W. Q. Zou, G. C. Guo, C. Z. Lu and J. S. Huang, Inorg. Chem., 2006, 45, 6308.

11 T. Fiedler, M. Hilder, P. C. Junk, U. H. Kynast, M. M. Lezhnina and M. Warzala, Eur. J. Inorg. Chem., 2007, 291.

12 (a) G. B. Deacon and R. J. Phillips, Coord. Chem. Rev., 1980, 33, 227; (b) E. E. S. Teotonio, H. F. Brito, M. C. F. C. Felinto, L. C. Thompson, V. G. Young and O. L. Malta, J. Mol. Struct., 2005, 751, 85.

13 (a) P. Mahata, K. V. Ramya and S. Natarajan, Chem.-Eur. J., 2008, 14, 5839; (b) B. T. N. Pham, L. M. Lund and D. Song, Inorg. Chem., 2008, 47, 6329; (c) A. W. Lam, W. Wong, S. Gao, G. Wen and X. Zhang, Eur. J. Inorg. Chem., 2003, 149.

14 G. B. Deacon, S. Hein, P. C. Junk, T. Jüstel, W. Lee and D. R. Turner, Cryst. Eng. Comm, 2007, 9, 1110 .

15 (a) H. W. Roesky and M. Andruh, Coord. Chem. Rev., 2003, 236, 91; (b) P. N. Remya, S. Biju, M. L. P. Reddy, A. H. Cowley and M. Findlater, Inorg. Chem., 2008, 47, 7396.

16 (a) J. Lorenc and A. Puszko, Chem. Heterocycl. Compd., 1998, 34, 674; (b) C. A. van Walree, V. E. M. K. Richters, S. J. Veen, B. Wieczorek, J. H. van der Wiel and B. C. van der Wiel, Eur. J. Org. Chem., 2004, 3046.

17 (a) M. Shi, F. Li, T. Yi, D. Zhang, H. Hu and C. Huang, Inorg. Chem., 2005, 44, 8929; (b) H. Xin, M. Shi, X. C. Gao, Y. Y. Huang, Z. L. Gong, D. B. Nie, H. Cao, Z. Q. Bian, F. Li and C. H. Huang, J. Phys. Chem. $B, 2004,108,10796$.

18 (a) N. Sabbatini, M. Guardigli and J.-M. Lehn, Coord. Chem. Rev, 1993, 123, 201; (b) V. Bekiari and P. Lianos, Adv. Mater., 1998, 10, 1455; (c) N. Sabbatini, A. Mecati, M. Guardigli, V. Balzani, J.-M. Lehn, R. Ziessel and R. Ungaro, J. Lumin., 1991, 463, 48; (d) K. Driesen, R. Van Deun, C. Gorller-Walrand and K. Binnemans, Chem. Mater., 2004, 16, 1531.

19 (a) L. N. Sun, J. B. Yu, G. L. Zheng, H. J. Zhang, Q. G. Meng, C. Y. Peng, L. S. Fu, F. Y. Liu and Y. N. Yu, Eur. J. Inorg. Chem., 2006, 3962; (b) M. Kawa and J. M. J. Frechet, Chem. Mater., 1998, 10, 286; (c) H. R. Li, J. Lin, H. J. Zhang, L. S. Fu, Q. G. Meng and S. B. Wang, Chem. Mater., 2002, 14, 3651; (d) S. Biju, M. L. P. Reddy, A. H. Cowley and K. V. Vasudevan, J. Mater. Chem., 2009, 19, 5179.

20 (a) J. Xia, B. Zhao, H.-S. Wang, W. Shi, Y. Ma, H.-B. Song, P. Cheng, D.-Z. Liao and S.-P. Yan, Inorg. Chem., 2007, 46, 3450; (b) W. T. Carnall, In Handbook on the Physics and Chemistry of Rare Earths, eds. K. A. Gschneidner L. Eyring, Elsevier, Amsterdam, The Netherlands, 
1987, vol. 3, Chapter 24, p. 171; (c) G. H. Dieke, Spectra and Energy levels of Rare Earth Ions in Crystals, Interscience, New York, 1968.

21 (a) S. Biju, D. B. Ambili Raj, M. L. P. Reddy and B. M. Kariuki, Inorg. Chem., 2006, 45, 10651; (b) R. Pavithran, N. S. Saleesh Kumar, S. Biju, M. L. P. Reddy, S. A. Junior and R. O. Freire, Inorg. Chem., 2006, 45, 2184; (c) R. Pavithran, M. L. P. Reddy, S. A. Junior, R. O. Freire, G. B. Rocha and P. P. Lima, Eur. J. Inorg. Chem., 2005, 4129; (d) D. B. Ambili Raj, S. Biju and M. L. P. Reddy, Inorg. Chem., 2008, 47, 8091.

22 (a) A. Dossing, Eur. J. Inorg. Chem., 2005, 1425; (b) A. Beeby, I. M. Clarkson, R. S. Dickins, S. Faulkner, D. Parker, L. Royle, A. S. de Sousa, J. A. G. Williams and M. Woods, J. Chem. Soc., Perkin Trans., 1999, 2, 493.
23 M. Latva, H. Takalo, V. M. Mukkala, C. Matachescu, J. C. Rodriguez Ubis and J. Kanakare, J. Lumin., 1997, 75, 149.

24 F. J. Steemers, W. Verboom, D. N. Reinhoudt, E. B. Van der Tol and J. W. Verhoeven, J. Am. Chem. Soc., 1995, 117, 9408.

25 (a) A. Bril and A. W. De Jager-Veenis, J. Electrochem. Soc., 1976, 123, 396; (b) C. D. Mello Donega, S. A. Junior and G. F. de Sa, Chem. Commun., 1996, 1199; (c) L. D. Carlos, C. D. Mello Donega, R. Q. Albuquerque, S. A. Junior, J. F. S. Menezes and O. L. Malta, Mol. Phys., 2003, 101, 1037.

26 G. M. Sheldrick, SHELL-PC, Version 5, Siemens Analytical X-ray Instruments. Inc., Madison, WI, USA, 1994. 